\title{
Tuning culturing conditions towards the production of neutral lipids from lubricant-based wastewater in open mixed bacterial communities
}

\author{
Ana Rita Castro a , Pedro T.S. Silva ${ }^{a, 1}$, Paulo J.G. Castro ${ }^{a, 2}$, Eliana Alves ${ }^{\mathrm{b}}$, \\ M. Rosário M. Domingues ${ }^{\mathrm{b}}$, Maria Alcina Pereira ${ }^{\mathrm{a}, ~ *}$ \\ ${ }^{a}$ CEB - Centre of Biological Engineering, University of Minho, Campus de Gualtar, 4710-57 Braga, Portugal \\ ${ }^{\mathrm{b}}$ Mass Spectrometry Centre, Department of Chemistry \& QOPNA, University of Aveiro, Campus Universitário de Santiago, $3810-193$ Aveiro, Portugal
}

\section{A R T T I C L E I N F O}

\section{Article history:}

Received 27 March 2018

Received in revised form

26 July 2018

Accepted 28 July 2018

Available online 30 July 2018

\section{Keywords:}

Oily wastewater

Bacterial lipid

Triacylglycerol

Bacterial enrichment

Cultivation conditions

Response surface methodology

\begin{abstract}
A B S T R A C T
Production of bacterial lipid-based biofuels using inexpensive substrates, as wastes, is an emerging approach. In this work, a selective process using carbon feast-famine cycles was applied to obtain an indigenous microbial community of hydrocarbon-degrading and lipid-accumulating bacteria, using a real lubricant-based wastewater as carbon source. In the conditions applied, the enriched bacterial community, dominated by members of the genus Rhodococcus, Pseudomonas and Acinetobacter, was able to degrade almost all hydrocarbons present in the wastewater within $24 \mathrm{~h}$ ' incubation and to accumulate, although in low levels, triacylglycerol (TAG) $(<5 \%$ of cell dry weight $(\mathrm{CDW}))$ and polyhydroxyalkanoates (PHA) $(3.8 \% \pm 1.1 \%$ of the CDW) as well as an unknown lipid $(29 \% \pm 6 \%$ of $\mathrm{CDW})$, presumably a wax esterlike compound. The influence of culture conditions, namely carbon and nitrogen concentrations (and C/N ratio) and cultivation time, on the amount and profile of produced storage compounds was further assessed using a statistical approach based on a central composite circumscribed design and surface response methodology. The regression analysis of the experimental design revealed that only nitrogen concentration and $\mathrm{C} / \mathrm{N}$ ratio are significant for neutral lipid biosynthesis $(\mathrm{p}<0.05)$. Maximum neutral lipid content, i.e. 33\% (CDW basis), was achieved for the lowest carbon and nitrogen concentrations evaluated $\left(10 \mathrm{~g} \mathrm{COD} \mathrm{L}^{-1}\right.$ and $\left.0.02 \mathrm{~g} \mathrm{~N} \mathrm{~L}^{-1}\right)$. PHA accounted for less than $5 \%$ of CDW. In these conditions, neutral lipid content was mainly composed by TAG, about 70\% (w/w). TAG precursors, namely monoacylglycerols (MAG), diacylglycerols (DAG) and fatty acids (FA), accounted for $22 \%$ of total neutral lipids and WE for about 7\%. Nevertheless, according to the applied response surface model, further improvement of neutral lipids content is still possible if even lower nitrogen concentrations are used. The fatty acids detected in TAG extracts ranged from myristic acid (C14:0) to linoleic acid (C18:2), being the most abundant palmitic acid (C16:0), stearic acid (C18:0) and oleic acid (C18:1).

This study shows the feasibility of combining treatment of hydrocarbon contaminated wastewater, herein demonstrated for lubricant-based wastewater, with the production of bacterial neutral lipids using open mixed bacterial communities. This approach can decrease the costs associated to both processes and contribute to a more sustainable waste management and production of lipid-based biofuels.
\end{abstract}

(๑) 2018 Elsevier Ltd. All rights reserved.

\footnotetext{
* Corresponding author. Universidade do Minho, Departamento de Engenharia Biológica, Campus de Gualtar, 4710-057 Braga, Portugal.

E-mail address: alcina@deb.uminho.pt (M.A. Pereira).

1 Present address: Department of Chemical Engineering, Loughborough University, Epinal way, Loughborough, Le11 3EP, UK.

2 Present address: Instituto de Tecnologia Química e Biológica António Xavier, Universidade Nova de Lisboa, Av. da República, 2780-157 Oeiras, Portugal.
}

\section{Introduction}

Increasing request for petroleum-derived products has led to a rapid development of several types of oil-based industries. As a consequence, considerable amounts of different hydrocarbon contaminated wastes are produced, the most significant being oily sludge and oily wastewaters. Oily wastewaters are produced from several industries, namely crude oil production and refinement, 


\begin{tabular}{|c|c|c|c|}
\hline \multicolumn{2}{|c|}{ List of abbreviations } & \multirow{2}{*}{$\begin{array}{l}\text { MAG } \\
\text { MAH } \\
\text { OD }\end{array}$} & \multirow{2}{*}{$\begin{array}{l}\text { Monoacylglycerol } \\
\text { Monocyclic aromatic hydrocarbons } \\
\text { Optical density }\end{array}$} \\
\hline CCCD & Central composite circumscribed design & & \\
\hline CDW & Cellular dry weight & PAH & Polycyclic aromatic hydrocarbons \\
\hline $\mathrm{C} / \mathrm{N}$ & Carbon to nitrogen ratio & PHA & Polyhydroxyalkanoate, PHB Polyhydroxybutyrate, \\
\hline COD & Chemical oxygen demand & & PHV Polyhydroxyvalerate \\
\hline DAG & Diacylglycerol & Q-TOF & Quadrupole time-of-flight \\
\hline DGGE & Denaturating gradient gel electrophoresis & SPE & Solid phase extraction \\
\hline ESI-MS & Electrospray ionization-mass spectrometry & TAG & Triacylglycerol \\
\hline FA & Fatty acid & TLC & thin-layer chromatography \\
\hline \multirow[t]{2}{*}{ GC-FID } & Gas chromatography coupled to flame ionization & $\mathrm{TN}$ & Total nitrogen \\
\hline & detection & WE & Wax esters \\
\hline GC-MS & Gas chromatography coupled to mass spectrometry & & \\
\hline
\end{tabular}

lubricants and petrochemical manufacturing, automotive repair stations and industrial equipment maintenance unit and automobile repair shops. This type of wastewaters is mainly composed by complex mixtures of alkanes, aromatic hydrocarbons, phenols, asphaltenes, emulsified oils, solvents and lubricants (Bhattacharya et al., 2003), which present a major environmental concern. Currently applied treatment and disposal methods are neither effective nor efficient solutions. In particular, they are not costeffective neither eco-friendly, and this type of waste corresponds to a loss of economic competitiveness for their source companies.

Production of bacterial storage lipids during biological treatment of hydrocarbon-based wastewaters has been recently proposed as a way to make management of these wastes more economic and environmentally sustainable (Da Silva et al., 2016). Hydrocarbonoclastic bacteria have the ability to degrade a wide range of hydrocarbon compounds: branched, unbranched and cyclic alkanes as well as aromatics, namely monocyclic aromatic hydrocarbons (MAH) and polycyclic aromatic hydrocarbons (PAH). These bacteria can be found in several distinct ecosystems, including marine waters, soils and sediments, especially in oil-polluted ones (Bragg et al., 1994; Harayama et al., 2004; Head et al., 2006). Some of the most representative genera are Alcanivorax, Pseudomonas, Acinetobacter and Rhodococcus (Koma et al., 2001; Larkin et al., 2005; Cappello et al., 2007; Palleroni et al., 2010). In addition to biodegradation capabilities, members of these groups can produce storage compounds, namely triacylglycerol (TAG), wax esters (WE) and polyhydroxyalkanoates (PHA) (Alvarez et al., 2002; Manilla-Pérez et al., 2011; Chen et al., 2014), which can be used as raw materials for the production of feed additives, cosmetics, lubricants, biofuels and bioplastics (Steinbüchel and Füchtenbusch, 1998; Alvarez and Steinbüchel, 2010).

The process of bacterial neutral lipids production and accumulation is complex and the amount and type of carbon storage is highly dependent on several parameters, such as the species itself, carbon source type and cultivation conditions. Neutral lipids accumulation is promoted under unbalanced growth conditions, when an excess of carbon is present but low levels of nitrogen occur, resulting in a high ratio of carbon to nitrogen in the culture medium (Manilla-Pérez et al., 2011; Alvarez and Steinbüchel, 2010; Olukoshi and Packter, 1994). In general, cells in the initial and exponential growth phase do not produce significant amounts of lipids, whereas in the stationary phase, there is a drastic increase (Packter and Olukoshi, 1995; Wältermann et al., 2005). Wältermann and Steinbüchel 2005 described that under conditions of cell proliferation, Rhodococcus opacus PD630 produced low levels of TAG and Acinetobacter calcoaceticus ADP1 accumulated low TAG and WE. However, when transferred to nitrogen limiting conditions, both bacteria increased significantly TAG and WE content after $24 \mathrm{~h}$. Several works reported differences occurring between species in terms of quantity and type of carbon storage compounds production. Several Rhodococcus strains grown on glucose and gluconate accumulated TAG as a major storage compound and PHAs in lower amounts, whereas with hexadecane only TAG were produced (Alvarez et al. 1997, 2008; Alvarez, 2003). Rhodococcus ruber is a peculiar strain since it accumulates considerable PHA and TAG levels, but PHA production occurs already in exponential growth phase and TAG are only produced after, when cells enter the stationary growth phase (Alvarez et al., 2000). Members of the genera Alcanivorax and Acinetobacter present different neutral lipids profiles, when compared to Rhodococcus. In a general way, WE are the most dominant storage lipid in these bacteria, whereas TAG are produced in lower amounts, depending on the carbon source used. Alcanivorax borkumensis SK2 accumulated predominantly TAG when cultivated on pyruvate and similar levels of TAG and WE with hexadecane (Manilla-Pérez et al., 2011). More recently, A. borkumensis SK2 fed with lubricant-based wastewater, produced the highest TAG levels in stationary growth phase, whereas maximum production of WE-like compounds was achieved during exponential growth phase (Da Silva et al., 2016).

Due to the complexity of factors influencing storage compounds production, several works regarding the optimization of lipid storage compounds and the influence of cultivation conditions were reported using pure bacterial cultures (Gouda et al., 2008, Kurosawa et al., 2010, Kurosawa and Sinskey, 2014). From a practical point of view, however, studies with open mixed microbial cultures should be considered since mixed cultures facilitate the use of cheap complex substrates (wastes) and avoid the need for sterilization and sterile operation conditions (Reis et al., 2003).

In this work, a mixed bacterial community able to produced storage compounds was enriched with a real lubricant-based wastewater and the influence of several culture conditions, namely carbon and nitrogen concentrations ( $\mathrm{C} / \mathrm{N}$ ratio) and cultivation time, on the profile of storage compounds produced was further assessed using a statistical approach, based on a design of experiments.

\section{Materials and methods}

The experimental approach included two consecutive experiments, experiment 1 and experiment 2, as depicted in Fig. 1.

\subsection{Experiment 1 - Selection of indigenous hydrocarbonoclastic bacteria able to accumulate neutral lipids}

\subsubsection{Inoculum and wastewater source}

Sludge collected in February 2011 (5 L) from the aeration vessel 

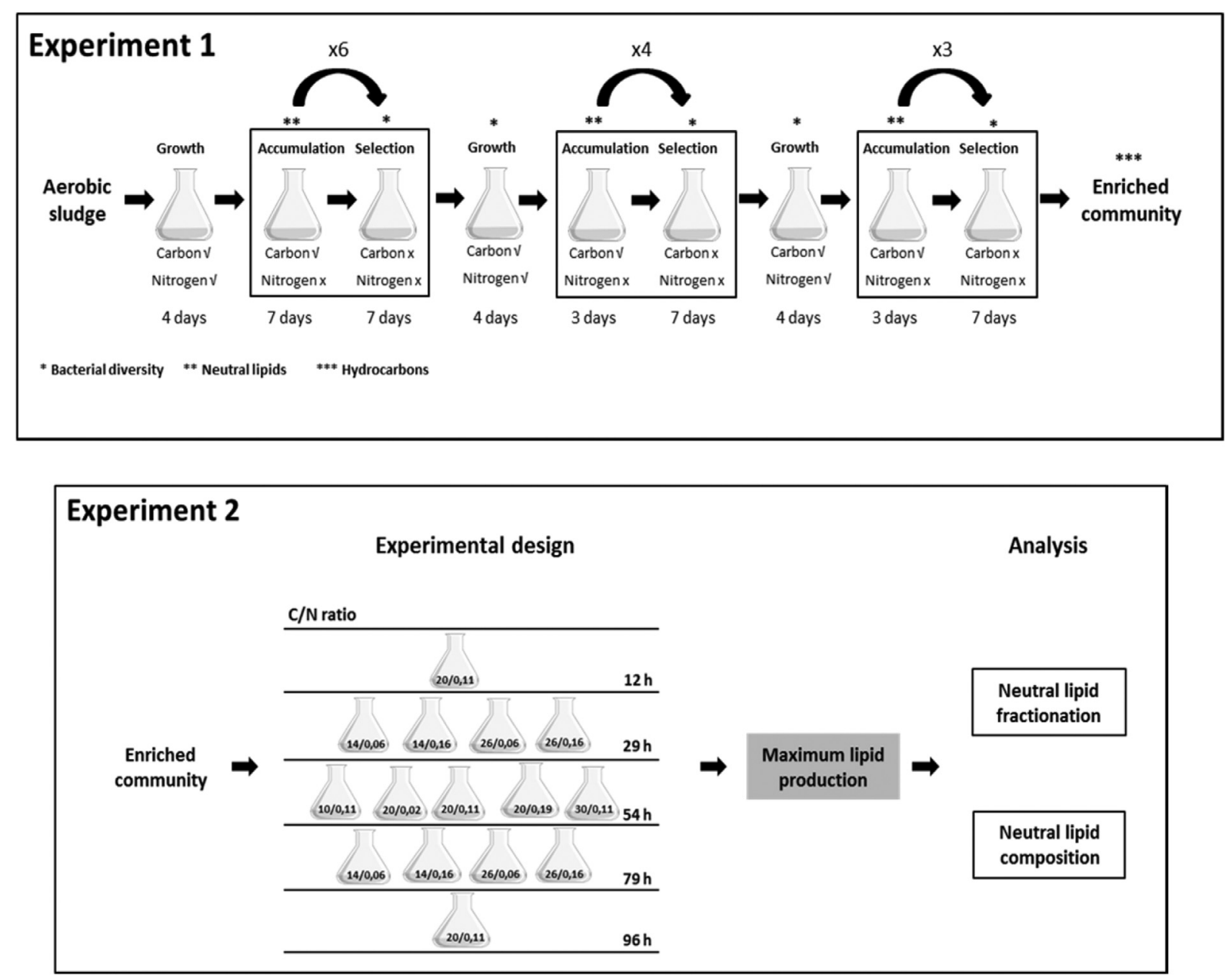

Fig. 1. Schematic diagram representing the experimental procedure of experiment 1 and experiment 2.

of a wastewater treatment plant located in a heavy machinery maintenance service unit (ALSTOM Portugal, S.A., Maia) was used as inoculum. Wastewater collected from the same service unit $(10 \mathrm{~L})$, containing lubricant and engine oil waste, was used as carbon source for the enrichment process. The wastewater treatment plant included a gravimetric oil/water separation unit and subsequent aeration of the separated water fraction in the collector vessel (to promote aerobic degradation of remaining hydrocarbons by indigenous microorganism) before being discharged to the municipal collector. The wastewater was kept at $0{ }^{\circ} \mathrm{C}$ to guarantee the original composition. It was characterized by a high Chemical Oxygen Demand (COD) $\left(307 \pm 14 \mathrm{~g} \mathrm{~L}^{-1}\right)$, and high amounts of total petroleum hydrocarbons $\left(720 \mathrm{~g} \mathrm{~kg}^{-1}\right.$ dry weight (DW)). Total ammonia nitrogen was present in very low amounts $\left(0.13 \pm 0.4 \mathrm{mg} \mathrm{L}^{-1}\right)$. The concentration of total and organic nitrogen was $172 \pm 18 \mathrm{mg} \mathrm{L}^{-1}$ and $77 \pm 9 \mathrm{mg} \mathrm{L}^{-1}$, respectively, whereas nitrates concentration was $94 \pm 9 \mathrm{mg} \mathrm{L}^{-1}$. No nitrites were detected. The wastewater $\mathrm{pH}$ was slightly acid (5.5).

\subsubsection{Selective enrichment process}

The enrichment process was performed in batch mode using $250 \mathrm{~mL}$ flasks with $50 \mathrm{~mL}$ of mineral salt (MS) medium (Schlegel et al., 1961) at room temperature $\left(22^{\circ} \mathrm{C}\right)$ under agitation $(150 \mathrm{rpm})$. The inoculum was first submitted to a growth stage (carbon rich, nitrogen rich) in MS medium supplemented with the hydrocarbon-rich wastewater $\left(5 \mathrm{~g} \mathrm{COD} \mathrm{L}^{-1}\right)$ as sole carbon source and ammonium chloride $\left(0.5 \mathrm{~g} \mathrm{~L}^{-1}\right)$ as nitrogen source, during 4 days, to obtain high biomass levels. Afterwards, selective pressure was applied in the form of alternating accumulation (carbon rich (5 $\mathrm{g} \mathrm{COD} \mathrm{L}^{-1}$ ), no nitrogen) and selection (no carbon and no nitrogen) stages. Cells were collected by centrifugation $\left(4^{\circ} \mathrm{C}, 10 \mathrm{~min}\right.$, $10000 \mathrm{~g}$ ) and transferred to the next stage in fresh MS medium. The accumulation and selection stages lasted 7 days each. After 6 cycles of accumulation and selection (C1-C6), a growth phase of 4 days was promoted in order to obtain higher biomass levels. To increase the selective pressure, 7 cycles of accumulation and selection were performed, changing the accumulation phase from 7 to 3 days (C7C13). Between cycles 9 and 10 and at the end of cycle 13 a growth stage was again performed to obtain higher biomass levels. Cyclosporine $\left(10 \mu \mathrm{g} \mathrm{mL}^{-1}\right)$ was used to inhibit fungal growth. The total process lasted 13 cycles, corresponding to 4 months. Biomass samples were collected at the end of the accumulation stages of cycles 3, 5, 6, 10,11 and 13 for analysis of carbon storage compounds production, at the end of selection and growth stages of cycles 3, 6, 10 and 13 for molecular characterization of bacterial community diversity and at the end of the enrichment process for hydrocarbon analysis.

\subsection{Experiment 2- Effect of culturing conditions on neutral lipids accumulated by the mixed bacterial community}

\subsubsection{Inoculum and assay conditions}

Production of carbon storage compounds by the bacterial community obtained in the selective enrichment process 
(experiment 1), under different conditions of COD, $\mathrm{N}$, and incubation times, was studied in $250 \mathrm{~mL}$ flasks containing $50 \mathrm{~mL}$ of $\mathrm{MS}$ medium supplemented with ammonium chloride $\left(\mathrm{NH}_{4} \mathrm{Cl}\right)$ as nitrogen source at room temperature $\left(22^{\circ} \mathrm{C}\right)$ under agitation $(150 \mathrm{rpm})$. The enriched microbial community was first grown in the presence of a COD concentration of $5 \mathrm{~g} \mathrm{~L}^{-1}$ of wastewater and $0.5 \mathrm{~g} \mathrm{~L}^{-1}$ of $\mathrm{NH}_{4} \mathrm{Cl}$ to obtain high biomass levels. Grown cells were used to inoculate the flasks to an optical density (OD) at $600 \mathrm{~nm}$ of 1.0.

\subsubsection{Factorial experimental design and statistical analysis}

A factorial central composite circumscribed design (CCCD) based on surface response methodology was used to study the effect of cultivation conditions (factors) and its possible interactions, on neutral lipids accumulated by the enriched bacterial community. The three factors (independent variables) selected were COD concentration, $\mathrm{N}$ concentration and incubation time. For each independent variable five levels were chosen $(:-a,-1,0,+1,+a$, where $\mathrm{a}=2 \mathrm{n} / 4 ; \mathrm{n}=$ number of parameters and 0 corresponded to the central level), resulting in a total of 32 experiments (including duplicates and a quadruplicate central point). The experimental levels were selected by varying the parameters above and below the respective central level. The coded and uncoded levels of the independent variables are given in Table 1 . The experiments were performed in duplicate in a random way. The software package Design-Expert ${ }^{\circledR}$ (Stat-Ease, Inc., Minneapolis) was used to perform the design matrix of the experiments subjected to regression analysis and their statistical evaluation.

The experimental results were analysed to assess the effects of each variable as well as their interaction effects by the response surface regression procedure using the following equation:

$Y_{i}=\beta_{0}+\sum \beta_{i} X_{i}+\sum \beta_{i} X_{1}^{2}+\sum \beta_{i j} X_{i} X_{j}$

Where $Y_{i}$ is the response variable, $\beta_{0}$ is the constant, $\beta_{i}$ is the linear effect, $\beta_{\mathrm{ij}}$ is the interactive effect and $X_{\mathrm{i}}$ is the coded factor level. The results were analysed by using ANOVA, i.e. analysis of variance, suitable for the experimental design. Statistical significance was established at the $\mathrm{p}<0.05$ level.

At the end of each experiment, all cell content of the flasks was collected, centrifuged, lyophilized and stored in a desiccator until further lipid and PHA analysis.

\subsection{Bacterial community analysis}

\subsubsection{DNA extraction}

Aliquots of well-homogenized biomass were immediately frozen at the time of sampling and stored at $-20^{\circ} \mathrm{C}$. Total genomic DNA was extracted using a FastDNA SPIN Kit for Soil (Qbiogene, Carlsbad, CA, USA) according to the manufacturer's instructions.

Table 1

Independent variables and levels used in central composite circumscribed design (CCC) for the production of storage compounds by enriched bacterial community.

\begin{tabular}{|c|c|c|c|c|c|c|}
\hline \multirow[t]{5}{*}{ Variable } & \multirow[t]{5}{*}{ Units } & \multicolumn{5}{|l|}{ Level } \\
\hline & & \multicolumn{5}{|c|}{ Coded values } \\
\hline & & -1.68 & -1 & 0 & +1 & +1.68 \\
\hline & & \multirow[t]{2}{*}{$(-)$} & & & & $(+)$ \\
\hline & & & & \multicolumn{3}{|l|}{ Real values } \\
\hline COD & $\mathrm{g} \mathrm{L}^{-1}$ & 10.0 & 14.05 & 20.0 & 25.95 & 30.0 \\
\hline $\mathrm{N}$ & $\mathrm{g} \mathrm{L}^{-1}$ & 0.056 & 0.083 & 0.129 & 0.16 & 0.250 \\
\hline Time & Hours & 12 & 29 & 54 & 79 & 96 \\
\hline
\end{tabular}

\subsubsection{DGGE analysis}

The 16S rRNA genes were amplified by PCR using a Taq DNA Polymerase kit (Life Technologies, Gaithersburg, MD, USA). All primers used were synthesized commercially by Invitrogen (Life Technologies). Primer set 968-f/1401-r (Muyzer et al., 1993) was used for amplification of the regions V6 to V8 of the 16S rRNA gene, for denaturing gradient gel electrophoresis (DGGE) purpose. Primer 968-f was modified by the addition of a 40 -bp GC clamp at the $5^{\prime}$ end of the sequence. The thermocycling program used for this amplification was: predenaturation at $95^{\circ} \mathrm{C}$ for $2 \mathrm{~min}$; 35 cycles of denaturation at $95^{\circ} \mathrm{C}$ for $30 \mathrm{~s}$, annealing at $56^{\circ} \mathrm{C}$ for $40 \mathrm{~s}$ and elongation at $72{ }^{\circ} \mathrm{C}$ for $90 \mathrm{~s}$, and postelongation at $72{ }^{\circ} \mathrm{C}$ for $5 \mathrm{~min}$.

DGGE analysis of the amplicons was performed in a Dcode system (Bio-Rad, Hercules, CA, USA) with $8 \%(\mathrm{v} / \mathrm{v})$ polyacrylamide gels and a denaturant gradient of $30-60 \%$ or $40-60 \%$. A $100 \%$ denaturing solution was defined as $7 \mathrm{M}$ urea and $40 \%$ formamide. Electrophoresis was performed for $16 \mathrm{~h}$ at $85 \mathrm{~V}$ in $0.5 \mathrm{X}$ TAE buffer at $60^{\circ} \mathrm{C}$. DGGE gels were stained with AgNO3 according to the procedure previously described by (Sanguinetti and Simpson, 1994).

DGGE profiles were compared with the Neighbour Joining clustering method (Saitou and Nei, 1987) using the PyElph software version 1.4 (Pavel and Vasile, 2012). The distance matrix was calculated using the Dice coefficient (Dice, 1945).

\subsubsection{Sequencing by Illumina}

The composition of bacterial community was assessed from the variable V1-V3 regions of the 16S rRNA gene by high throughput sequencing, using the specific bacterial primer set $28 \mathrm{~F} / 388 \mathrm{R}$. Amplification, library preparation, sequencing and taxonomic assignment of $16 \mathrm{~S}$ rRNA reads were done by Research and Testing Laboratory-RTL, using an Illumina MiSeq platform and an Illumina two-step method described by (Caporaso et al., 2012). Chimeric sequences and sequences with less than $100 \mathrm{bp}$ were discarded. Clustering was performed at a $4 \%$ divergence using the USEARCH algorithm (Edgar, 2010) and OTUs selection (97\% identity threshold) was performed using the UPARSE algorithm (Edgar, 2013). The centroid sequence from each OTU cluster was run against the USERCH global alignment algorithm and taxonomic assignment done using a database of high-quality sequences derived from the NCBI nucleotide database. Detailed information on the bioinformatics analysis steps can be found at the RTL website (http://rtlgenomics.com/amplicon-bioinformatics-pipeline).

Bacterial community diversity was assessed by the Shannon diversity index (Shannon (1948)).

Illumina sequencing data was submitted to the European Nucleotide Archive, under the study accession number PRJEB25660, and can be viewed by following the URL: http://www. ebi.ac.uk/ena/data/view/PRJEB25660.

\subsection{Analytical methods}

Chemical oxygen demand (COD), total nitrogen (TN), ammonium $\left(\mathrm{NH}_{4}^{+}\right)$, phosphate $\left(\mathrm{PO}_{4}^{3-}\right)$, nitrates, nitrites and total ammonia nitrogen present in the wastewater were determined using the cuvette-tests Lck914, Lck338, Lck386, Lck305, Lck340, Lck341 and Lck303, respectively (Hach-Lange, Germany). These measurements were made in triplicate, according to the manufacturer's procedures.

\subsection{Neutral lipids analysis}

\subsubsection{Neutral lipids extraction and analysis by TLC}

Lipids were extracted according to Folch method (Folch et al., 1957), with some modifications. For this, $15 \mathrm{mg}$ of lyophilized cells were extracted with $3 \mathrm{~mL}$ of a mixture of chloroform/ 
methanol (2:1, v/v) (Wältermann et al., 2000). The mixture was incubated at room temperature with shaking for two hours. Afterwards, the cell extracts were obtained after filtration through glass wool and evaporated to dryness.

Analysis of lipid profiles was performed by thin-layer chromatography (TLC). The extracts were dissolved in chloroform/methanol $(2: 1, \mathrm{v} / \mathrm{v})$ and applied on $10 \times 10 \mathrm{~cm}$ glass DC-Fertigplatten plates, precoated with $0.25 \mathrm{~mm}$ silica gel 60 with fluorescent indicator UV254 (60F254 silica gel plates - Merck, Darmstadt, Germany). The TLC was performed applying the following developing solvent system: hexane/diethyl ether/acetic acid (80:20:1, v/v/v) as mobile phase for separation of acylglycerols (Wältermann et al., 2000).

Neutral lipids were visualized on the-plates after brief exposure to iodine vapor. Olive oil, oleic acid, and oleyl oleate were used as standard substances for TAG, fatty acids and WE, respectively.

\subsubsection{Fractionation of different lipid classes}

Total lipid extracts were subjected to a separation process based on lipid class using a solid phase extraction (SPE) technique (Revellame et al., 2012). The extract was reconstituted in $n$-hexane $(1 \mathrm{~mL})$ and applied on a SPE silica column ( $\mathrm{SiOH})$ Chromabond 1000-mg, 6 mL, (Macherey-Nagel, Düren, Germany), previously conditioned with $n$-hexane. The sample was then fractionated into four main fractions: fraction $A$, enriched in hydrocarbons; fraction $B$, enriched in wax esters and sterol esters; fraction $C$ enriched in triacylglycerols and fraction $D$, enriched in free fatty acids, monoacyglycerols and diacylglycerols. Fraction A was eluted by applying $3.7 \mathrm{~mL}$ of $94: 6(\mathrm{v} / \mathrm{v}) n$-hexane/diethyl ether; fraction B was obtained by applying $4.5 \mathrm{~mL}$ of $94: 6(\mathrm{v} / \mathrm{v}) \mathrm{n}$-hexane/diethyl ether; fraction $C$ was eluted by applying $10 \mathrm{~mL}$ of $94: 6(\mathrm{v} / \mathrm{v}) \mathrm{n}$-hexane/ diethyl ether; fraction $\mathrm{D}$ was obtained applying $15 \mathrm{~mL}$ of 85:15:2 (v/ $\mathrm{v} / \mathrm{v}) n$-hexane/diethyl ether/acetic acid. The fraction volumes were optimized based on TLC analysis. All fractions were collected, evaporated to dryness and weighted.

Fractions B, C and D, corresponding to total neutral lipid compounds, were gravimetrically quantified. Each fraction was scraped from the TLC plates transferred to a Pasteur pipet filled with cotton wool and eluted from the silica, using hexane as solvent (Santala et al., 2011).

\subsubsection{Neutral lipids analysis by ESI-MS}

Fractions B, C and D were analysed by mass spectrometry (MS) through electrospray ionization (ESI) obtained in a quadrupole time-of-flight (Q-TOF) mass spectrometer (Q-TOF2, Micromass, Manchester, UK) and fraction D was also analysed in an LXQ linear ion trap mass spectrometer (Thermo Scientific, San Jose, CA, USA). ESI-MS and MS/MS conditions in the Q-TOF mass spectrometer were the following: electrospray voltage was $3 \mathrm{kV}$ in positive-ion mode with a cone voltage of $30 \mathrm{~V}$; the source temperature was $80^{\circ} \mathrm{C}$ and the desolvation temperature was $150^{\circ} \mathrm{C}$. Collision energy used for the MS/MS analysis varied between 30 and $40 \mathrm{eV}$. Data acquisition and treatment of results was carried out with the MassLynx ${ }^{\mathrm{TM}}$ software V4.0 (Waters, Manchester, UK). ESI-MS and MS/MS conditions used in the linear ion trap mass spectrometer were the following: electrospray voltage was $4.7 \mathrm{kV}$ in negative-ion mode; capillary temperature was $275^{\circ} \mathrm{C}$, and the sheath gas (He) flow rate was 25 units. For MS/MS acquisition, the normalized collision energy (CE) varied between 33 and 40 (arbitrary units). Data acquisition and treatment of results were carried out with the Xcalibur $^{\circledR}$ Data System 2.0 (Thermo Scientific, San Jose, CA, USA).

\subsection{PHA extraction and quantification}

Accumulation of PHA (polyhydroxybutyrate and polyhydroxyvalerate) by the microbial community was determined according to the procedure described in Smolders et al. (1994). Freeze-dried biomass of each sample was weighed $(8-20 \mathrm{mg}$ ) into digestion tubes. $1.5 \mathrm{~mL}$ of internal standard benzoic acid in dichloromethane $\left(1 \mathrm{mg} \mathrm{mL}^{-1}\right)$ and $1.5 \mathrm{~mL}$ of 1 propanol:hydrochloric acid $(75: 25 \mathrm{v} / \mathrm{v})$ were added. The tubes were placed in a digester block at $100{ }^{\circ} \mathrm{C}$ for $3.5 \mathrm{~h}$.

Samples were analysed by gas chromatography (GC) with flame ionization detector (GD-FID). The GC equipment was a GC Varian 3800, Varian Inc. USA with a TR-WAX (Teknokroma, Spain) column, $30 \mathrm{~m} \times 0.32 \mathrm{~mm} \times 0.25 \mathrm{~mm}$. The injector and detector temperatures were $220^{\circ} \mathrm{C}$ and $250^{\circ} \mathrm{C}$, respectively. Column temperature was $50^{\circ} \mathrm{C}$ for $2 \mathrm{~min}$, with a $15^{\circ} \mathrm{C} \mathrm{min}{ }^{-1}$ ramp to $225^{\circ} \mathrm{C}$, and a final hold at $225^{\circ} \mathrm{C}$ for $5 \mathrm{~min}$. Helium was used as carrier gas at $1 \mathrm{~mL} \mathrm{~min}^{-1}$.

\subsection{Total hydrocarbons extraction and analysis}

Hydrocarbon content in the wastewater was analysed at SGS Portugal (Sociedade Geral de Superintendência, S.A.) according to DIN EN 14039/EN ISO 16703.

Extraction of the hydrocarbons present in the culture media was performed based on procedures disclosed in NJDEP EPH 10/08 (NJDEP, 2010) and began with the acidification of the media with hydrochloric acid to a pH below 2.0. Acidified media were transferred to $50 \mathrm{~mL}$ separatory funnels. Then, $7.5 \mathrm{~mL}$ of chloroform: methanol $(3: 1, \mathrm{v} / \mathrm{v})$ was added to each flask and transferred to the corresponding separatory funnel (Koma et al., 2001). The separatory funnels were vigorously stirred for $2 \mathrm{~min}$ and then allowed to rest for 5 min to allow the organic and aqueous phase separation and the organic phases were carefully collected. This process was performed three times. This process was also performed in control flasks, corresponding to the beginning of the assays.

The extracts were cleaned on Florisil Sep-Pak columns $6 \mathrm{cc}$ (Waters, USA) adapted to a vacuum manifold. The columns were equilibrated with $6 \mathrm{~mL}$ of methanol:chloroform $(3: 1, \mathrm{v} / \mathrm{v})$ and the samples were passed through the columns to new flasks. Then, additional $6 \mathrm{~mL}$ of solvent were passed through the columns to remove any remaining hydrocarbons. The samples were allowed to evaporate in the fume hood, suspended in $1.5 \mathrm{~mL}$ of hexane and analysed by GC-FID.

Gas chromatography was performed in a GC $\operatorname{Varian}^{\circledR}$ star $3400 C X$ equipped with a VF- $1 \mathrm{~ms}$ column, $30 \mathrm{~m}$ long and $0.25 \mathrm{~mm}$ internal diameter, and made from fused silica coated with dimethylpolysiloxane as stationary phase. The column temperature was held at $60^{\circ} \mathrm{C}$ for $1 \mathrm{~min}$ and then programmed to raise up to $290^{\circ} \mathrm{C}$ at $8{ }^{\circ} \mathrm{C} \mathrm{min}^{-1}$. The injector temperature was set to $285^{\circ} \mathrm{C}$. Helium was used as carrier gas at a flow rate of $1 \mathrm{~mL} \mathrm{~min}^{-1}$. The detector was operated at $300^{\circ} \mathrm{C}$.

\section{Results and discussion}

\subsection{Selection of lipid-accumulating hydrocarbonoclastic communities}

Changes in the bacterial community structure during the selective enrichment process were followed by DGGE. The obtained DGGE profiles showed a decrease in bacterial diversity (decrease in number of bands) throughout time until the establishment of a relatively stable profile at the end of cycle 13 (C13f) (Fig. S1a). In particular, two predominant bands (stronger intensity) were detected at this time point, which probably corresponds to the most dominant bacteria in the developed community.

During the selective process, a significant shift in bacterial diversity was observed between cycle 6 and 10 (C6f and C10f profiles) 
(Fig. S1b) possibly related to the differences applied in terms of the duration of the accumulation phases. Until cycle 10 the accumulation stage lasted 7 days and in the further cycles the selective pressure was intensified, and it was degreased to 3 days. Therefore, the duration of the accumulation steps seems to significantly affect bacterial diversity of the enriched community.

The identification of bacterial species present in the microbial community at the beginning (Inoculum - I) and at the end of the enrichment process (cycle 13 - C13f) was performed by Illumina sequencing. From the results presented in Fig. 2 it can be seen that the inoculum had a high bacterial diversity (Shannon diversity index $\left(H^{\prime}\right)=1.59$ ), with most abundant 16S rRNA gene sequences belonging to the phylum Proteobacteria (67\% of relative dominance) and to orders Rhodocyclales (14\%), Rhizobiales (13\%), Chromatiales (12\%) and Burkholderiales (7\%). After the enrichment process, the bacterial community showed a considerable decrease in diversity (the $H^{\prime}$ index decreased from 1.59 to 0.89 ). The most dominant sequences corresponded to those with high similarity to members of the genus Acinetobacter (26\% relative dominance), Pseudomonas (31\%) and Rhodococcus (12\%) which are well known for their ability to produce wax esters (WE), polyhydroxyalkanoates (PHA) and triacylglycerols (TAG), respectively (Wältermann et al., 2000; Ishige et al., 2002; Tobin and O'Connor, 2005). The remaining sequences showed high similarity with members of the genera Acidovorax (14\%), Zoogloea (5\%) and Variovorax (3\%), which include species that have been described as capable of producing PHA (Fukui et al., 1976; Renner et al., 1996; Gasser et al., 2009).

The profile of neutral lipid storage compounds accumulated by the enriched bacterial community was evaluated through thin layer chromatography (TLC) (Fig. S2). In the initial phase of the enrichment (cycle 3), it was only possible to detect faint bands at the level of fatty acids, however, throughout the enrichment two distinct bands corresponding to TAG became visible ( $\mathrm{C} 5$ and $\mathrm{C6}$ ). These results are in agreement with the results of Illumina sequencing, where an increase in the dominance of sequences corresponding to Rhodococcus sp. and Rhodococcus erythropolis, known as TAG producers, was detected. A shift in TAG profile was observed in the next stages and only one single band was detected (C11 and C13), which can be related to the imposed decrease of the accumulation phase duration (from 7 to 3 days). TAG content produced by the bacterial community was however very low, below $5 \%$ of the cellular dry weight (Table S1). In the last 3 cycles of the enrichment (C11 and C13, Fig. S2) an intense band was detected between TAG and WE standards, which corresponded to $29 \%$ of the cellular dry weight. This unknown lipid may be a wax diester-like compound, as previously found by (Kalscheuer et al., 2003). According to this author, Acinetobacter calcoaceticus strain ADP1 is able to accumulate wax diesters under nitrogen limiting conditions, which resolve at similar TLC zone of the unknown lipid detected in this work. This result is supported by the phylogenetic identification of bacteria present at the end of the enrichment, where one of the most dominant bands corresponds to a member of the genus Acinetobacter.

In spite of the several PHA producers identified in the enriched bacterial community, PHA content was very low, around $4 \%$ of cellular dry weight (Table S1).

During the selective enrichment process, $\mathrm{pH}$ varied between 7.25 and 7.56 and dissolved oxygen concentration between 5 and $6 \mathrm{mg} \mathrm{L}^{-1}$ (Table S1).

The capacity of the enriched bacterial community to degrade the hydrocarbons present in the lubricant-based wastewater was further assessed at the end of the enrichment process. This wastewater is mainly composed by medium chain hydrocarbons, between $\mathrm{C} 9$ and $\mathrm{C} 12$, and a complex mixture in the range between C17 and C30 characterized by the presence of two significant GC- unresolved humps (Fig. S3 (A)). After $24 \mathrm{~h}$ ' incubation, the bacterial community was able to fully degrade the GC resolved hydrocarbons and a considerable part of the GC-unresolved ones. These results clearly demonstrated the feasibility of the developed enriched community to treat hydrocarbon-based wastewaters, supporting the phylogenetic identification that indicated the presence of hydrocarbon degrading-bacteria such as Pseudomonas, Acinetobacter and Rhodococcus genus (Larkin et al., 2005; Palleroni et al., 2010; Kostka et al., 2011).

The applied multistage enrichment process, with successive cycles of feast and famine, allowed the development of a community able to use the hydrocarbons present in the wastewater and produce storage lipids. The use of complex wastewater has the advantage to mimic a real treatment scenario. Real wastewater may contain indigenous microorganisms already adapted to the wastewater contaminants and to an environment of high carbon concentration and low levels of nitrogen, which favours lipid accumulation (Riesenberg and Guthke, 1999). The obtained lipid content was quite low suggesting that the cultivation conditions applied in the enrichment process can be improved.

\subsection{Influence of culturing conditions on storage compounds accumulation}

The microbial community enriched in hydrocarbonoclastic and lipid accumulating bacteria was further cultivated in different concentrations of carbon and nitrogen (resulting in different $\mathrm{C} / \mathrm{N}$ ratios) and different incubation times. The interactive effects of the tested variables (COD concentration (A), $\mathrm{N}$ concentration (B) and cultivation time (C)) in PHA and neutral lipid production (response variable) were assessed.

In all assays, PHA content was lower than $5 \%$ and, thus, further analysis concerning this storage compound was not performed.

\subsubsection{Neutral lipids accumulation}

Neutral lipids accumulation in the assays performed in the conditions determined by the experimental design is described in Table 2. The lowest neutral lipid content measured was between 1 and $5 \%$ of the CDW for $79 \mathrm{~h}$ of cultivation at a concentration of COD and nitrogen of $26 \mathrm{~g} \mathrm{~L}^{-1}$ and $0.0557 \mathrm{~g} \mathrm{~L}^{-1}$, respectively (C/N ratio $=116$ ). The highest values of neutral lipids detected in the enriched bacterial community was around 33\% of the CDW cultivated on $20 \mathrm{~g} \mathrm{COD} \mathrm{L}^{-1}, 0.0216 \mathrm{~g} \mathrm{~N} \mathrm{~L}^{-1}(\mathrm{C} / \mathrm{N}$ ratio $=231)$ after $54 \mathrm{~h}$ of cultivation. This result is in the range of values reported in other works, including the ones obtained with pure cultures of oleaginous bacteria proposed for neutral lipid production (more than $20 \%$ of lipids in cellular dry weight) (Manilla-Pérez et al., 2011; Revellame et al., 2012; Alvarez et al., 1996; Hernandéz and Alvarez, 2010; Tamis et al., 2015).

The experimental data described in Table 2 were used in the statistic Design-Expert software to perform multiple regression analysis and to generate a model representing the relation between independent and response variables. The generated second-order polynomial equation was established as follows:

$$
\begin{aligned}
\boldsymbol{Y}= & 9.81+0.14 \times \boldsymbol{A}-2.97 \times \boldsymbol{B}-1.57 \times \boldsymbol{C}+2.98 \times \boldsymbol{A} \times \boldsymbol{B} \\
& +0.033 \times \boldsymbol{A} \times \boldsymbol{C}+1.72 \times \boldsymbol{B} \times \boldsymbol{C}-1.68 \times \boldsymbol{A}^{2}+2.15 \times \boldsymbol{B}^{2} \\
& +2.50 \times \boldsymbol{C}^{2}
\end{aligned}
$$

In this equation, $\mathrm{Y}$ represents the neutral lipid content obtained by the bacterial community (\% CDW) and the terms $\mathrm{A}, \mathrm{B}$ and $\mathrm{C}$ are the coded values of the independent variables for carbon content ( $\mathrm{g}$ COD $\left.\mathrm{L}^{-1}\right)$, nitrogen content $\left(\mathrm{g} \mathrm{L}^{-1}\right)$ and cultivation time (hours), 


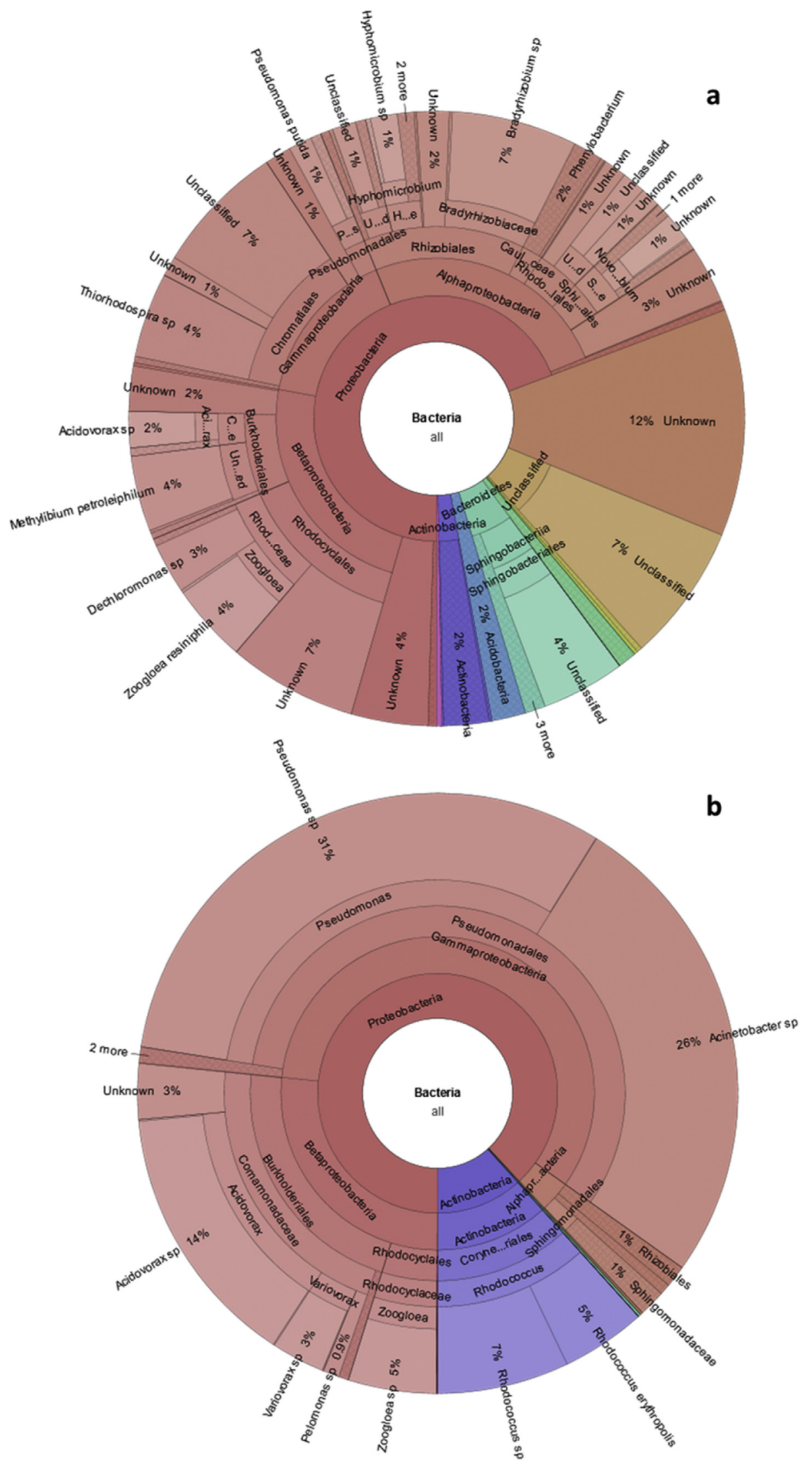

Fig. 2. Bacterial community composition until the species level at the a) beginning and at the b) end of the enrichment process. 
Table 2

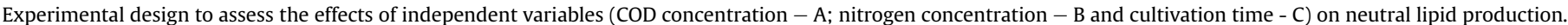

\begin{tabular}{|c|c|c|c|c|c|c|c|c|}
\hline \multirow[t]{2}{*}{ Experiment } & \multicolumn{3}{|l|}{ Coded values } & \multicolumn{3}{|l|}{ Actual values } & \multirow[t]{2}{*}{$\mathrm{C} / \mathrm{N}^{\mathrm{a}}$} & \multirow[t]{2}{*}{ \% Neutral lipids ( $\mathrm{g} \mathrm{g}^{-1} \mathrm{CDW}$ ) } \\
\hline & A: $\operatorname{COD}\left(\mathrm{g} \mathrm{L}^{-1}\right)$ & B: $N\left(\mathrm{~g} \mathrm{~L}^{-1}\right)$ & $C: t(h)$ & A: $\operatorname{COD}\left(\mathrm{g} \mathrm{L}^{-1}\right)$ & B: $N\left(\mathrm{~g} \mathrm{~L}^{-1}\right)$ & C: $t(h)$ & & \\
\hline 15 & 0 & 0 & -1.682 & 20 & 0.1058 & 12 & 47 & 23.9 \\
\hline 22 & 0 & 0 & -1.682 & 20 & 0.1058 & 12 & 47 & 24.1 \\
\hline 2 & -1 & -1 & -1 & 14 & 0.0557 & 29 & 63 & 15.4 \\
\hline 24 & -1 & -1 & -1 & 14 & 0.0557 & 29 & 63 & 15.5 \\
\hline 6 & 1 & -1 & -1 & 26 & 0.0557 & 29 & 116 & 10.5 \\
\hline 5 & 1 & -1 & -1 & 26 & 0.0557 & 29 & 116 & 10.8 \\
\hline 7 & -1 & 1 & -1 & 14 & 0.1559 & 29 & 23 & 7.5 \\
\hline 18 & -1 & 1 & -1 & 14 & 0.1559 & 29 & 23 & 10.2 \\
\hline 29 & 1 & 1 & -1 & 26 & 0.1559 & 29 & 42 & 6.9 \\
\hline 27 & 1 & 1 & -1 & 26 & 0.1559 & 29 & 42 & 14.7 \\
\hline 20 & -1.682 & 0 & 0 & 10 & 0.1058 & 54 & 24 & 5.9 \\
\hline 9 & -1.682 & 0 & 0 & 10 & 0.1058 & 54 & 24 & 8.3 \\
\hline 31 & 1.682 & 0 & 0 & 30 & 0.1058 & 54 & 71 & 11.0 \\
\hline 8 & 1.682 & 0 & 0 & 30 & 0.1058 & 54 & 71 & 9.3 \\
\hline 32 & 0 & -1.682 & 0 & 20 & 0.0216 & 54 & 231 & 33.5 \\
\hline 21 & 0 & -1.682 & 0 & 20 & 0.0216 & 54 & 231 & 30.0 \\
\hline 10 & 0 & 1.682 & 0 & 20 & 0.1900 & 54 & 26 & 10.4 \\
\hline 26 & 0 & 1.682 & 0 & 20 & 0.1900 & 54 & 26 & 3.9 \\
\hline 12 & 0 & 0 & 0 & 20 & 0.1058 & 54 & 47 & 14.6 \\
\hline 25 & 0 & 0 & 0 & 20 & 0.1058 & 54 & 47 & 7.0 \\
\hline 16 & 0 & 0 & 0 & 20 & 0.1058 & 54 & 47 & 12.5 \\
\hline 21 & 0 & 0 & 0 & 20 & 0.1058 & 54 & 47 & 7.6 \\
\hline 28 & -1 & -1 & 1 & 14 & 0.0557 & 79 & 63 & 8.6 \\
\hline 13 & -1 & -1 & 1 & 14 & 0.0557 & 79 & 63 & 14.7 \\
\hline 11 & 1 & -1 & 1 & 26 & 0.0557 & 79 & 116 & 1.2 \\
\hline 17 & 1 & -1 & 1 & 26 & 0.0557 & 79 & 116 & 4.6 \\
\hline 23 & -1 & 1 & 1 & 14 & 0.1559 & 79 & 23 & 8.8 \\
\hline 14 & -1 & 1 & 1 & 14 & 0.1559 & 79 & 23 & 4.6 \\
\hline 3 & 1 & 1 & 1 & 26 & 0.1559 & 79 & 42 & 8.1 \\
\hline 1 & 1 & 1 & 1 & 26 & 0.1559 & 79 & 42 & 15.1 \\
\hline 30 & 0 & 0 & 1.682 & 20 & 0.1058 & 96 & 47 & 12.3 \\
\hline 4 & 0 & 0 & 1.682 & 20 & 0.1058 & 96 & 47 & 21.4 \\
\hline
\end{tabular}

CDW - Cell dry weight.

a Molar carbon was estimated considering a ratio between COD and total organic carbon of about 4, based on the theoretical values calculated for saturated hydrocarbons with the general formula of $\mathrm{CnH} 2 \mathrm{n}+2$.

respectively. In order to investigate the adequacy of the model, multiple regression analyses on the data were applied and the statistical significance of the model was evaluated by means of ANOVA. Table 3 displays the coefficients and p-values of the independent variables as well as of their interaction on neutral lipids accumulation. ANOVA of the quadratic model indicated that the model is significant ( $p$-value $<0.05$ ), suggesting that the model was statistically significant with a confidence interval of $95 \%$ and suitable for revealing the relation of carbon concentration, nitrogen concentration and cultivation time and predicting the response values in terms of neutral lipid production (Fig. S4). The regression analysis of the experimental design revealed that only nitrogen concentration and the interaction between carbon and nitrogen concentrations are significant for neutral lipid biosynthesis $(\mathrm{p}<0.05)$.

Fig. 3 shows the effect of the interaction between carbon and nitrogen concentrations on neutral lipid accumulation at different cultivation times. Highest neutral lipid level, about 33\%, was predicted for 29 h' cultivation time with the lowest carbon and nitrogen concentrations analysed, namely $10 \mathrm{~g} \mathrm{COD} \mathrm{L}^{-1}$ and $0.02 \mathrm{~g} \mathrm{~N} \mathrm{~L}^{-1}$ $(\mathrm{C} / \mathrm{N}=126)$. The lowest level of neutral lipids (less than $1 \%$ ) was obtained by decreasing carbon concentration and increasing nitrogen concentration $(\mathrm{C} / \mathrm{N}=43)$. The amount of neutral lipids
Table 3

Degree of positive or negative effects of the experimental variables on neutral lipids production.

\begin{tabular}{lll}
\hline \multirow{2}{*}{ Factor } & \multicolumn{2}{l}{ Neutral lipids } \\
\cline { 2 - 3 } & Coefficient & P-value \\
\hline Model & & $<0.0429^{*}$ \\
$\mathrm{~A}-\mathrm{COD}$ & 0.14 & 0.9105 \\
$\mathrm{~B}-\mathrm{N}$ & -2.97 & $0.0215^{*}$ \\
$\mathrm{C}-\mathrm{t}$ & -1.57 & 0.2050 \\
$\mathrm{AB}$ & 2.98 & $0.0408^{*}$ \\
$\mathrm{AC}$ & 0.33 & 0.8364 \\
$\mathrm{BC}$ & 1.72 & 0.2834 \\
$\mathrm{~A}^{2}$ & -1.68 & 0.3000 \\
$\mathrm{~B}^{2}$ & 2.15 & 0.1872 \\
$\mathrm{C}^{2}$ & 2.50 & 0.1278 \\
\hline
\end{tabular}

${ }^{*} \mathrm{p}$ value $<0.05$

showed a less significant decreased to approximately $26 \%$ (for a $\mathrm{C} / \mathrm{N}$ ratio of 126). The response surface model does not attain an optimum value in the tested conditions suggesting that further improvement on neutral lipids levels accumulated may be obtained when even lower $\mathrm{N}$ concentrations are used. Previous reports have demonstrated that neutral lipid accumulation is highly dependent 


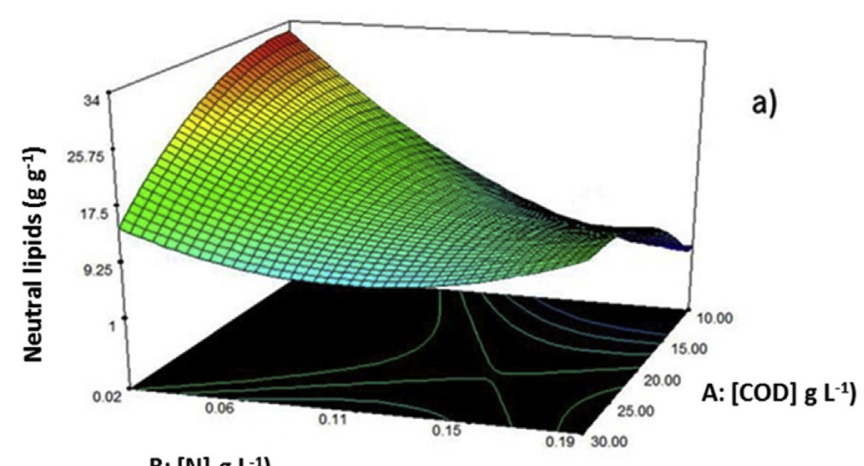

B: $\left.[\mathrm{N}] \mathrm{g} \mathrm{L}^{-1}\right)$

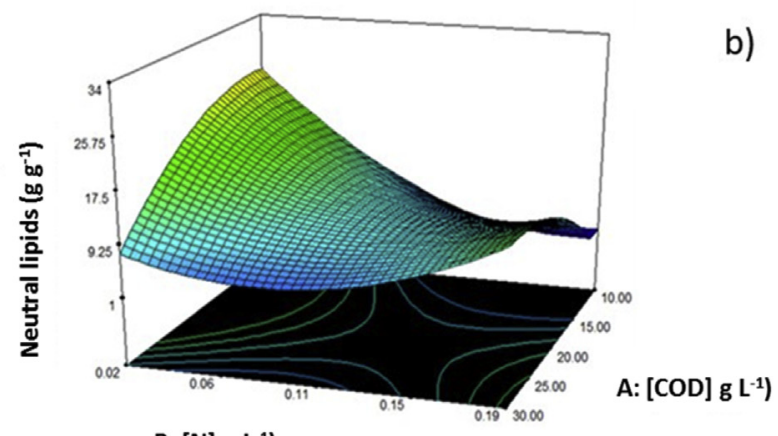

B: $\left.[N] \mathrm{g} \mathrm{L}^{-1}\right)$

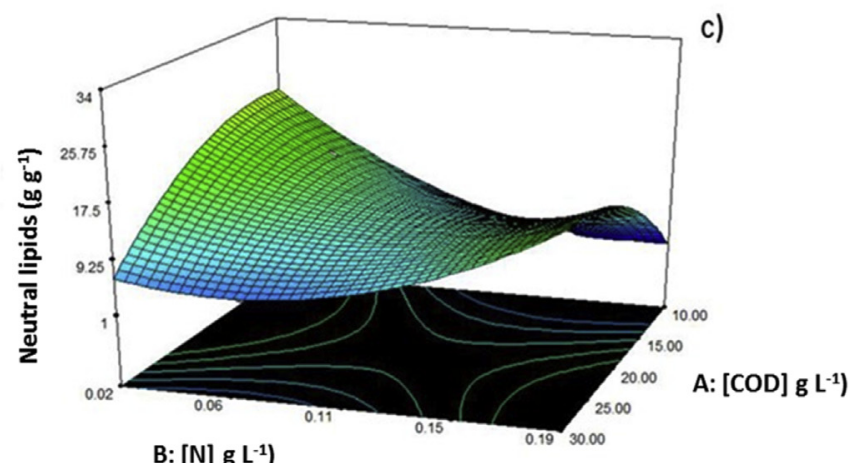

Fig. 3. Three-dimensional response surface plots showing the effect and interactions between the independent variables in neutral lipids accumulation. a) Interaction between carbon and nitrogen concentrations at $29 \mathrm{~h}$ of cultivation; b) Interaction between carbon and nitrogen concentrations at $54 \mathrm{~h}$ of cultivation; c) Interaction between carbon and nitrogen concentrations at $79 \mathrm{~h}$ of cultivation.

on several culturing conditions, $\mathrm{C} / \mathrm{N}$ being one of the most relevant in several types of bacteria (Riesenberg and Guthke, 1999). $R$. opacus PD630 cultivated on orange waste and glucose accumulated more TAG $(45-47 \% \mathrm{w} / \mathrm{w})$ at $\mathrm{C} / \mathrm{N}$ ratios $(\mathrm{g} / \mathrm{g})$ of 2400 and 16 , respectively, than at lower ratios $(C / N=266$ and $C / N=6$ ) (Gouda et al., 2008; Kurosawa et al., 2010). A. borkumensis SK2 grown in pyruvate presented the same behaviour. At a $\mathrm{C} / \mathrm{N}$ ratio of $50 \mathrm{accu}-$ mulated more TAG than at $\mathrm{C} / \mathrm{N}=7$ (Manilla-Pérez et al., 2011). Some authors reported a $\mathrm{C} / \mathrm{N}$ ratio ranging between 50 and 500 as optimal for TAG accumulation in Rhodococcus species grown on hydrocarbons and sugars (Alvarez et al., 1996, 1997; Alvarez, 2003; Gouda et al., 2008; Kurosawa et al., 2010). However, these studies were done with simple substrates, making it impossible to directly compare these values with the values used in this work.
The classes of neutral lipids accumulated by the bacterial community cultivated in conditions promoting maximum neutral lipid content (about 33\% of CDW) were further analysed by thin layer chromatography (TLC) (Fig. S5). TAG was the most abundant lipid, representing $70 \%(\mathrm{w} / \mathrm{w})$ of total neutral lipid content. Fatty acids (FA), monoacylglycerols (MAG) and diacylglycerols (DAG) were also found, accounting for $22 \%$ of total neutral lipids, whereas WE were produced in lower amounts, corresponding to $7 \%$ of total neutral lipids. The low levels of WE production may be related to the low dominance of WE producing bacteria present in the obtained enrichment (namely Acinetobacter genus) as suggested by Illumina sequencing (Fig. 2).

The composition of lipids extract fractions B to D (Fig. S5), was analysed by ESI-MS and ESI-MS/MS. The mass spectrometry analysis of fraction B showed no molecular species corresponding to wax esters or sterol esters. Table 4 describes the several TAG structures identified in fraction $\mathrm{C}$.

The most abundant TAG ions were found at $\mathrm{m} / \mathrm{z} 850.9,876.8$ and 902.8 identified as $\left[\mathrm{M}+\mathrm{NH}_{4}\right]^{+}$adducts of TAG(50:1), TAG(52:2) and TAG(54:3), respectively. The fatty acyl chains identified in TAG molecules ranged between myristic acid (C14:0) and linoleic acid (C18:2), being the most abundant species composed mainly by palmitic acid (C16:0), stearic acid (C18:0) and oleic acid (C18:1). The free fatty acids identified in fraction $D$ are presented in Table 5.

A wide range of free fatty acids were produced by the bacterial community, with carbon chain length ranging between 14 and 25 carbon atoms. Interestingly, odd-chain fatty acids, namely C15:0 and C17:0, and unsaturated fatty acids between one and five double bonds were also detected.

The structures of MAG and DAG produced by the enriched community are listed in Table 6. MAG are mainly composed by palmitic acid (C16:0), stearic acid (C18:0) and linoleic acid (C18:2), whereas DAG are composed by a mixture of palmitic acid (C16:0), oleic acid (C18:1), linoleic acid (C18:2) and linolenic acid (C18:3).

This wide range of TAG, free fatty acids, MAG and DAG structures possibly reflects the complex mixture of hydrocarbon types present in the wastewater used as carbon and energy source. In fact, these results are in agreement with previous reports, where a wide range of fatty acids were produced by a mixed microbial population present in municipal activated sludge and also by pure bacterial cultures, namely $R$. opacus PD630 and Gordonia sp. DG, when grown on real and complex agro-industrial wastes and municipal wastewaters (Gouda et al., 2008; Revellame et al., 2012). The fatty acid profile of the bacterial neutral lipids obtained in this work consisted

\section{Table 4}

Molecular species of triacylglycerols identified as $\left[\mathrm{M}+\mathrm{NH}_{4}\right]^{+}$ions detected by ESI-QTOF-mass spectrometry in fraction $\mathrm{C}$ of the cell extract obtained from the enriched community cultivated in conditions promoting maximum lipid content.

\begin{tabular}{lll}
\hline$m / z\left[\mathrm{M}+\mathrm{NH}_{4}\right]^{+}$ & Triacylglycerol $(\mathrm{C}: \mathrm{N})$ & Fatty acyl chains \\
\hline 822.9 & $48: 1$ & $16: 0 / 16: 0 / 16: 1$ \\
& & $14: 0 / 16: 0 / 18: 1$ \\
848.9 & $50: 2$ & $16: 0 / 16: 1 / 18: 1$ \\
& & $16: 0 / 16: 0 / 18: 2$ \\
& & $18: 1 / 18: 1 / 14: 0$ \\
& & $16: 1 / 16: 1 / 18: 0$ \\
850.9 & $50: 1$ & $14: 0 / 18: 0 / 18: 2$ \\
\cline { 2 - 3 } 874.9 & & $16: 0 / 16: 0 / 18: 1$ \\
& $52: 3$ & $14: 0 / 18: 0 / 18: 1$ \\
876.9 & & $16: 0 / 16: 1 / 18: 0$ \\
\hline 902.9 & $52: 2$ & $16: 0 / 18: 1 / 18: 2$ \\
\cline { 2 - 3 } & $54: 3$ & $16: 1 / 18: 1 / 18: 1$ \\
\hline
\end{tabular}


Table 5

Molecular species of free fatty acids identified as [M-H] ${ }^{-}$ions detected by ESI-ion trap -mass spectrometry in fraction $\mathrm{C}$ of the cell extract obtained from the enriched community cultivated in conditions promoting maximum lipid content.

\begin{tabular}{ll}
\hline$m / z[\mathrm{M}-\mathrm{H}]^{-}$ & Fatty acyl chains \\
\hline 227.2 & $14: 0$ \\
241.2 & $15: 0$ \\
253.2 & $16: 1$ \\
255.2 & $16: 0$ \\
269.2 & $17: 0$ \\
281.3 & $18: 1$ \\
283.3 & $18: 0$ \\
301.2 & $20: 5$ \\
303.2 & $20: 4$ \\
307.2 & $20: 2$ \\
309.2 & $20: 1$ \\
311.3 & $20: 0$ \\
325.2 & $21: 0$ \\
337.2 & $22: 1$ \\
339.2 & $22: 0$ \\
367.3 & $24: 0$ \\
381.3 & $25: 0$ \\
\hline
\end{tabular}

\section{Table 6}

Molecular species of monoacylglycerols and diacylglycerols identified as $\left[\mathrm{M}+\mathrm{NH}_{4}\right]^{+}$ ions detected by ESI-Q-TOF-mass spectrometry in fraction $\mathrm{C}$ of the cell extract obtained from the enriched community cultivated in conditions promoting maximum lipid content.

\begin{tabular}{lllll}
\hline$m / z\left[\mathrm{M}+\mathrm{NH}_{4}\right]^{+}$ & \multicolumn{2}{l}{ Monoacyglycerols } & & \multicolumn{2}{l}{ Diacylglycerols } \\
\cline { 2 - 2 } & $\mathrm{C}: \mathrm{N}$ & & & \\
348. & $16: 0$ & & & \\
372.4 & $18: 2$ & & \\
376.4 & $18: 0$ & $34: 3$ & $16: 0 / 18: 3$ \\
\hline 608.6 & & $34: 2$ & $16: 0 / 18: 2$ \\
610.6 & & $34: 1$ & $16: 0 / 18: 1$ \\
612.6 & & $36: 6$ & $18: 3 / 18: 3$ \\
630.6 & & $36: 5$ & $18: 2 / 18: 3$ \\
632.6 & & $36: 4$ & $18: 2 / 18: 2$ \\
634.6 & & & & \\
\hline
\end{tabular}

$\mathrm{C}: \mathrm{N}$ means total number of carbons:total number of double bonds.

mainly of the five most common C16-C18 fatty acids present in the feedstocks traditionally used for biodiesel production, showing its suitable use for lipid-based biofuels production.

\section{Conclusions}

This study shows the feasibility of combining treatment of hydrocarbon contaminated wastewater, herein demonstrated for lubricant-based wastewater, with the production of bacterial neutral lipids, using open mixed bacterial communities. In the tested conditions, neutral lipids content in the biomass could be increased up to 33\% (CDW basis), mainly composed by TAG (about $70 \% \mathrm{w} / \mathrm{w}$ ), by changing the culturing conditions, namely carbon and nitrogen ratio. However, further improvement of this content is still possible, as predicted by the response surface model applied to study the effect of culture conditions on neutral lipids biosynthesis, if even lower concentrations, in particular of nitrogen, are used.

This study also showed that indigenous microbial community (present in the wastewater/wastewater treatment plant) can be selectively enriched on lipid-accumulating bacteria, being potential resources for obtaining high-value compounds. Additionally, the use of hydrocarbon-rich wastewaters, which are cheap raw materials, can significantly reduce the production and commercialization costs of the obtained lipids as well as to mitigate environmental pollution by decreasing the amount of wastes that have to be treated. In this way, this study opens new perspectives to develop more economic and environmentally sustainable processes to manage this type of wastes.

\section{Acknowledgements}

This work was financially supported by the Portuguese Science Foundation (FCT) and European Social Fund (ESF, POPH-QREN) through the grant given to A.R. Castro (SFRH/BD/64500/2009), the FCT Strategic Project of UID/BIO/04469/2013 unit, COMPETE 2020 (POCI-01-0145-FEDER-006684 and POCI-01-0145-FEDER030180) and BioTecNorte operation (NORTE-01-0145-FEDER000004) funded by the European Regional Development Fund under the scope of Norte2020 - Programa Operacional Regional do Norte. The authors also thank to FCT/MEC for the financial support to the QOPNA research Unit (FCT UID/QUI/00062/2013), through national founds and where applicable co-financed by the FEDER, within the PT2020 Partnership Agreement, and to the Portuguese NMR Network. Eliana Alves is also grateful to FCT for her postdoctoral fellowship (BPD/UI51/5441/2014) supported by the project REDE/1504/REM/2005 and her individual post-doc fellowship (SFRH/BPD/109323/2015).

\section{Appendix A. Supplementary data}

Supplementary data related to this article can be found at https://doi.org/10.1016/j.watres.2018.07.068.

\section{References}

Alvarez, H., Mayer, F., Fabritius, D., Steinbüchel, A., 1996. Formation of intracytoplasmic lipid inclusion by Rhodococcus opacus PD630. Arch. Microbiol. 165, 377-386.

Alvarez, H.M., Kalscheuer, R., Steinbüchel, A., 1997. Accumulation of storage lipids in species of Rhodococcus and Nocardia and effect of inhibitors and polyethylene glycol. Lipid/Fett 99 (7), 239-246.

Alvarez, H.M., Kalscheuer, R., Steinbüchel, A., 2000. Accumulation and mobilization of storage lipids by Rhodococcus opacus PD630 and Rhodococcus ruber NCIMB 40126. Appl. Microbiol. Biotechnol. 54 (2), 218-223.

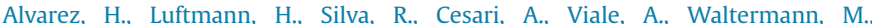
Steinbüchel, A., 2002. Identification of phenyldecanoic acid as a constituent of triacylglycerols and wax ester produced by Rhodococcus opacus PD630. Microbiology 148, 1407-1412.

Alvarez, H., 2003. Relationship between beta-oxidation pathway and the hydrocarbon-degrading profile in actinomycetes bacteria. Int. Biodeterior. Biodegrad. 52, 35-42.

Alvarez, A., Alvarez, H., Kalscheuer, R. Waltermann, M. Steinbüchel, A, 2008. Cloning and characterization of a gene involved in triacylglycerol biosynthesis and identification of additional homologous genes in the oleaginous bacterium Rhodococcus opacus PD630. Microbiology 154 (8), 2327-2335.

Alvarez, H., Steinbüchel, A., 2010. In: Alvarez, H.M. (Ed.), Biology of Rhodococcus. Springer Berlin Heidelberg, pp. 263-290.

Bhattacharya, D., Sarma, P.M., Krishnan, S., Mishra, S., Lal, B., 2003. Evaluation of genetic diversity among Pseudomonas citronellolis strains isolated from oily sludge-contaminated Sites. Appl. Environ. Microbiol. 69 (3), 1435-1441.

Bragg, J.R., Prince, R.C., Harner, E.J., Atlas, R.M., 1994. Effectiveness of bioremediation for the Exxon Valdez oil spill. Nature 368 (6470), 413-418.

Caporaso, J.G., Lauber, C.L., Walters, W.A., Berg-Lyons, D., Huntley, J., Fierer, N., Owens, S.M., Betley, J., Fraser, L., Bauer, M., Gormley, N., Gilbert, J.A., Smith, G., Knight, R., 2012. Ultra-high-throughput microbial community analysis on the Illumina HiSeq and MiSeq platforms. ISME J. 6 (8), 1621-1624.

Cappello, S., Denaro, R., Genovese, M., Giuliano, L., Yakimov, M.M., 2007. Predominant growth of Alcanivorax during experiments on "oil spill bioremediation" in mesocosms. Microbiol. Res. 162 (2), 185-190.

Chen, Y., Huang, Y.-C., Lee, C.-Y., 2014. Production and characterization of mediumchain-length polyhydroxyalkanoates by Pseudomonas mosselii T07. J. Biosci. Bioeng. 118 (2), 145-152.

Da Silva, P.D.M.P., Lima, F. Alves, M.M., Bijmans, M.F.M., Pereira, M.A., 2016. Valorization of lubricant-based wastewater for bacterial neutral lipids production: growth-linked biosynthesis. Water Res. 101, 17-24.

Dice, L.R., 1945. Measures of the amount of ecologic association between species. Ecology 26 (3), 297-302.

Edgar, R.C., 2010. Search and clustering orders of magnitude faster than BLAST. Bioinformatics 26 (19), 2460-2461. 
Edgar, R.C., 2013. UPARSE: highly accurate OTU sequences from microbial amplicon reads. Nat. Methods 10, 996-998.

Folch, J., Lees, M., Sloane Stanley, G., 1957. A simple method for the isolation and purifcation of total lipides from animal tissues. J. Biol. Chem. 226, 497-509.

Fukui, T., Yoshimoto, A., Matsumoto, M., Hosokawa, S., Saito, T., Nishikawa, H. Tomita, K., 1976. Enzymatic synthesis of poly- $\beta$-hydroxybutyrate in Zoogloea ramigera. Arch. Microbiol. 110 (2-3), 149-156.

Gasser, I., Müller, H., Berg, G., 2009. Ecology and characterization of polyhydroxyalkanoate-producing microorganisms on and in plants. FEMS (Fed. Eur. Microbiol. Soc.) Microbiol. Ecol. 70, 142-150.

Gouda, M., Omar, S., Aouad, L., 2008. Single cell oil production by Gordonia sp. DG using agro-industrial wastes. World J. Microbiol. Biotechnol. 24 (9), 1703-1711.

Harayama, S., Kasai, Y., Hara, A., 2004. Microbial communities in oil-contaminated seawater. Curr. Opin. Biotechnol. 15 (3), 205-214.

Head, I., Jones, D., Roling, W., 2006. Marine microorganisms make a meal of oil. Nat. Rev. Microbiol. 4, 173-182.

Hernandéz, M.A., Alvarez, H.M., 2010. Glycogen formation by Rhodococcus species and the effect of inhibition of lipid biosynthesis on glycogen accumulation in Rhodococcus opacus PD630. FEMS (Fed. Eur. Microbiol. Soc.) Microbiol. Lett. 312 (1), 93-99.

Ishige, T., Tani, A., Takabe, K., Kawasaki, K., Sakai, Y., Kato, N., 2002. Wax Ester production from n-alkanes by Acinetobacter sp. Strain M-1: ultrastructure of cellular inclusions and role of acyl Coenzyme A reductase. Appl. Environ. Microbiol. 68 (3), 1192-1195.

Kalscheuer, R., Uthoff, S., Luftmann, H., Steinbüchel, A., 2003. In vitro and in vivo biosynthesis of wax diesters by an unspecific bifunctional wax ester synthase/ acyl-CoA:diacylglycerol acyltransferase from Acinetobacter calcoaceticus ADP1. Eur. J. Lipid Sci. Technol. 105 (10), 578-584.

Koma, D., Hasumi, F., Yamamoto, E., Ohta, T., Chung, S.-Y., Kubo, M., 2001. Biodegradation of long-chain n-paraffins from waste oil of car engine by Acinetobacter sp. J. Biosci. Bioeng. 91 (1), 94-96.

Kostka, J.E., Prakash, O., Overholt, W.A., Green, S.J., Freyer, G., Canion, A., Delgardio, J., Norton, N., Hazen, T.C., Huettel, M., 2011. Hydrocarbon-degrading bacteria and the bacterial community response in Gulf of Mexico beach sands impacted by the deepwater Horizon oil spill. Appl. Environ. Microbiol. 77 (22), $7962-7974$

Kurosawa, K., Boccazzi, P., de Almeida, N., Sinskey, A., 2010. High-cell-density batch fermentation of Rhodococcus opacus PD630 using a high glucose concentration for triacylglycerol production. J. Biotechnol. 147 (3-4), 212-218.

Kurosawa, K., Sinskey, J.A., 2014. Triacylglycerol production from corn stover using a xylose-fermenting Rhodococcus opacus strain for lignocellulosic biofuels. Microbial and Biochemical Technology 6 (5), 254-259.

Larkin, M.J., Kulakov, L.A., Allen, C.C.R., 2005. Biodegradation and Rhodococcus masters of catabolic versatility. Curr. Opin. Biotechnol. 16 (3), 282-290.

Manilla-Pérez, E., Lange, A.B., Luftmann, H., Robenek, H., Steinbüchel, A., 2011. Neutral lipid production in Alcanivorax borkumensis SK2 and other marine hydrocarbonoclastic bacteria. Eur. J. Lipid Sci. Technol. 113 (1), 8-17.

Muyzer, G., de Waal, E.C., Uitterlinden, A.G., 1993. Profiling of complex microbial populations by denaturing gradient gel electrophoresis analysis of polymerase chain reaction-amplified genes coding for 16S rRNA. Appl. Environ. Microbiol. 59 (3), 695-700.

Olukoshi, E.R., Packter, N.M., 1994. Importance of stored triacylglycerols in Streptomyces: possible carbon source for antibiotics. Microbiology 140 (4), 931-943.
Packter, N.M., Olukoshi, E.R., 1995. Ultrastructural studies of neutral lipid localisation in Streptomyces. Arch. Microbiol. 164 (6), 420-427.

Palleroni, N.J., Pieper, D.H., Moore, E.R.B., 2010. In: Timmis, K. (Ed.), Handbook of Hydrocarbon and Lipid Microbiology. Springer Berlin Heidelberg, pp. 1787-1798.

Pavel, A.B., Vasile, C.I., 2012. PyElph - a software tool for gel images analysis and phylogenetics. BMC Bioinf. 13, 9.

Reis, M.A.M., Serafim, L.S., Lemos, P.C., Ramos, A.M., Aguiar, F.R., Van Loosdrecht, M.C.M., 2003. Production of polyhydroxyalkanoates by mixed microbial cultures. Bioproc. Biosyst. Eng. 25 (6), 377-385.

Renner, G., Haage, G., Braunegg, G., 1996. Production of short-side-chain poly hydroxyalkanoates by various bacteria from the rRNA superfamily III. Appl. Microbiol. Biotechnol. 46 (3), 268-272.

Revellame, E.D., Hernandez, R., French, W., Holmes, W.E., Benson, T.J., Pham, P.J. Forks, A., Callahan Ii, R., 2012. Lipid storage compounds in raw activated sludge microorganisms for biofuels and oleochemicals production. RSC Adv. 2 (5), 2015-2031.

Riesenberg, D., Guthke, R., 1999. High-cell-density cultivation of microorganisms Appl. Microbiol. Biotechnol. 51 (4), 422-430.

Saitou, N., Nei, M., 1987. The neighbor-joining method: a new method for reconstructing phylogenetic trees. Mol. Biol. Evol. 4 (4), 406-425.

Sanguinetti, C.J., Simpson, A.J., 1994. Rapid silver staining and recovery of PCR products separated on polyacrylamide gels. Biotechniques 17 (5), 914-921.

Santala, S., Efimova, E., Kivinen, V., Larjo, A., Aho, T., Karp, M., Santala, V., 2011. Improved triacylglycerol production in Acinetobacter baylyi ADP1 by metabolic engineering. Microb. Cell Factories 10 (1), 36.

Schlegel, H., Kaltwasser, H., Gottschalk, G., 1961. Ein Submersverfahren zur Kultu wasserstoffoxidierender Bakterien: wachstumsphysiologische Untersuchungen, Arch. Mikrobiol. 38, 209-222.

Shannon, C.E., 1948. A mathematical theory of communication. Bell System Technical Journal 27, 379-423 and 623-656.

Smolders, G.J.F., van der Meij, J., van Loosdrecht, M.C.M., Heijnen, J.J., 1994. Model of the anaerobic metabolism of the biological phosphorus removal process: stoichiometry and pH influence. Biotechnol. Bioeng. 43 (6), 461-470.

Steinbüchel, A., Füchtenbusch, B., 1998. Bacterial and other biological systems for polyester production. Trends Biotechnol. 16 (10), 419-427.

Tamis, J.S., Sorokin, D.Y., Jiang, Y., van Loosdrecht, M.C.M., Kleerebezem, R., 2015. Lipid recovery from a vegetable oil emulsion using microbial enrichment cultures. Biotechnol. Biofuels 8, 39.

Tobin, K.M., O'Connor, K.E., 2005. Polyhydroxyalkanoate accumulating diversity of Pseudomonas species utilising aromatic hydrocarbons. FEMS (Fed. Eur. Microbiol. Soc.) Microbiol. Lett. 253 (1), 111-118.

Wältermann, M., Luftmann, H., Baumeister, D., Kalscheuer, R., Steinbüchel, A., 2000. Rhodococcus opacus strain PD630 as a new source of high-value single-cell oil? Isolation and characterization of triacylglycerols and other storage lipids. Microbiology 146 (5), 1143-1149.

Wältermann, M., Hinz, A., Robenek, H., Troyer, D., Reichelt, R., Malkus, U., Galla, H.-J. Kalscheuer, R., Stöveken, T. Von Landenberg, P., Steinbüchel, A., 2005. Mechanism of lipid-body formation in prokaryotes: how bacteria fatten up. Mol Microbiol. 55 (3), 750-763.

Wältermann, M., Steinbüchel, A., 2005. Neutral lipid bodies in prokaryotes: recent insights into structure, formation, and relationship to eukaryotic lipid depots. J. Bacteriol. 187 (11), 3607-3619. 